\section{The Benefits of Attending the Annual Biomedical Research Conference for Minority Students (ABRCMS): The Role of Research Confidence}

\author{
Bettina J. Casad, ‘* Amy L. Chang, ${ }^{\ddagger}$ and Christine M. Pribbenow ${ }^{\S}$ \\ tDepartment of Psychological Sciences, University of Missouri-St. Louis, St. Louis, MO 63121;

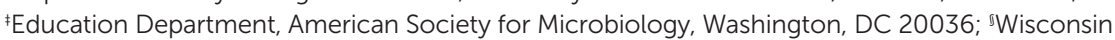 \\ Center for Education Research, Madison, WI 53706
}

\begin{abstract}
The Annual Biomedical Research Conference for Minority Students (ABRCMS) is designed to support undergraduate students' professional development as future scientists. Juniors, seniors, and postbaccalaureates who attended ABRCMS during 2008-2011 were emailed a link to an online questionnaire in which they reported their experiences at the conference. Attendees reported many ABRCMS-provided benefits. Frequency of attending or presenting at ABRCMS is positively related to science self-efficacy, research confidence, sense of belonging in science, and intentions to pursue a research degree in graduate school. Increased research confidence predicts graduate school plans and intentions for a research career in science; however, men were slightly more likely to intend to pursue a research career than women, likely due to higher research confidence. Although all attendees benefited from ABRCMS, underrepresented minority (URM) students had higher science self-efficacy and sense of belonging in science after attending ABRCMS than non-URM students. This finding demonstrates the effectiveness of ABRCMS as an intervention to increase the representation and success of URMs in science. Results highlight the importance of attending a minority-oriented research conference where URMs can develop their science self-efficacy, research confidence, and sense of belonging in science. However, changes to the conference and undergraduate research experiences may be necessary to reduce gender gaps.
\end{abstract}

\section{INTRODUCTION}

National attention is directed at broadening the participation of diverse groups in the life sciences educational pipeline and research career paths. Despite the increasing numbers of racial/ethnic minorities who complete baccalaureate degrees in the life sciences, their representation among National Institutes of Health (NIH) R01 grant recipients (Wadman, 2012) and tenure-track research faculty remains small (National Center for Educational Statistics, 2014). For example, in 2010, only 1\% of NIH principal investigators were black and 4\% were Hispanic, whereas 16\% were Asian and 71\% were Caucasian (Wadman, 2012). Both the NIH and the National Science Foundation (NSF) have dedicated federal funds to study the causes of underrepresentation of women and racial/ethnic minorities in the life sciences and for interventions that address these disparities (NIH, 2015; NSF, 2015).

A widely used theoretical framework to investigate the underrepresentation of racial/ethnic minorities in the life sciences is social cognitive career theory (SCCT; Lent et al., 1994, 2000, 2005, 2008). SCCT describes the role of cognitive person variables (e.g., self-efficacy, expected outcomes) in predicting career and academic interests and plans. SCCT further considers how these cognitive person variables interact with other characteristics of the person (e.g., gender, race) and with aspects of the cultural environment (e.g., supports and barriers) to predict academic and career
Pat Marsteller Monitoring Editor

Submitted January 15, 2016; Revised June 20, 2016; Accepted June 21, 2016

CBE Life Sci Educ September 1, 2016 15:ar46 DOI:10.1187/cbe.16-01-0048

*Address correspondence to: Bettina J. Casad (casadbj@umsl.edu).

(c) 2016 B. J. Casad et al. CBE-Life Sciences Education @ 2016 The American Society for Cell Biology. This article is distributed by The American Society for Cell Biology under license from the author(s). It is available to the public under an Attribution-Noncommercial-Share Alike 3.0 Unported Creative Commons License (http://creativecommons.org/licenses/ by-nc-sa/3.0)

"ASCB®" and "The American Society for Cell Biology ${ }^{\prime}$ " are registered trademarks of The American Society for Cell Biology. 
intentions. Although we do not test SCCT in the present investigation, this work guided our selection of variables of interest. We focused on psychological factors known to predict degree persistence and career trajectories in the sciences, including science self-efficacy, research confidence, and sense of belonging in science.

Research informed by SCCT has been used to develop effective interventions to increase the numbers of racial/ethnic minorities who pursue science careers (e.g., Luzzo et al., 1999; Byars-Winston et al., 2011; Maton et al., 2012; Thakore et al., 2014). Much has been written about the benefits of one type of intervention - undergraduate research experiences-as a way to engage students early in science, technology, engineering, and mathematics (STEM) fields (Kardash, 2000; Lopatto, 2004; Russell et al., 2007). For example, we know that students who have meaningful and engaging research experiences (Lopatto, 2003) are more likely to persist in their major (Chang et al., 2011) and pursue a career or graduate education in their discipline (Lopatto, 2004; Russell et al., 2007). Many studies document the psychological mechanisms for these gains, including increased science self-efficacy (Berkes, 2007; Chemers et al., 2001, 2011), research confidence (Seymour et al., 2004), and strengthened sense of belonging in science (Estrada et al., 2011). Science self-efficacy is the extent to which individuals believe they have the capabilities to become scientists. Research self-confidence, a similar construct to self-efficacy, is specific to individuals' confidence in their ability to learn and apply specific research skills, such as analyzing data, rather than their overall ability to become scientists. Students can have high research confidence in their ability to analyze data and present at conferences but may still doubt their ability to become a scientist. Finally, sense of belonging is an individual's feeling of connection and engagement in the scientific community.

Although much prior research has investigated the impact of undergraduate research experiences on degree and career plans, an understudied aspect in this literature is the benefits of attending and presenting research at professional conferences. The current project investigates the benefits of attending or presenting research at the Annual Biomedical Research Conference for Minority Students (ABRCMS). Of particular interest is how attending or presenting at ABRCMS relates to psychological factors known to predict degree persistence and career trajectories in the sciences, including science self-efficacy, research confidence, and sense of belonging in science.

\section{The Annual Biomedical Research Conference for Minority Students}

ABRCMS is managed by the American Society for Microbiology (ASM) and is funded by a T36 grant from the National Institute of General Medical Sciences (NIGMS) Division of Training, Workforce Development, and Diversity. ABRCMS began in 2000 and has become one of the largest professional conferences focused on the scientific training of underrepresented students in STEM disciplines. In 2015, the conference hosted 4080 attendees, including 2089 undergraduates and postbaccalaureates; 443 graduate students and postdoctoral scientists; and 1548 faculty, program directors, and administrators (ASM, 2015). ABRCMS provides a forum for underrepresented minority (URM) students to present their independent research and to learn more about education, training, and career oppor- tunities in STEM. The conference spans 4 days, during which nearly 1700 undergraduate students representing 12 STEM disciplines present their research as posters or oral presentations. The presentations are judged, and the top presenters are given awards during the closing banquet.

Conference Activities. A unique feature of ABRCMS is that students experience the conference as a cohort and engage in developmentally appropriate activities focused on exposure and training in scientific research and preparation for advancement in science. That is, students do not simply attend ABRCMS to present a poster or talk; instead, they are engaged with a community of scientists and practice "thinking like a scientist." For example, students attend webinars before the conference to learn how to write good abstracts, develop clear and organized posters, and present in a logical and persuasive manner. On the first day of the conference, all students must attend an orientation that is conducted in two sessions, one for sophomores and juniors and one for seniors and postbaccalaureates. In the orientation, students learn how to read the conference program, review posters, develop thoughtful questions, identify a purpose and plan for networking with prospective research advisers or graduate school administrators, and in general become acclimated to the scientific community.

The conference includes concurrent professional development sessions targeted at undergraduates and postbaccalaureates on topics such as transitioning from 2- to 4-year colleges, writing a personal statement, applying to graduate school, choosing a $\mathrm{PhD}$ program or taking the $\mathrm{MD}-\mathrm{PhD}$ path, graduate student life, presentation techniques, networking, getting published, research funding programs, and career outlook in STEM. The conference includes plenary sessions for all attendees on current and important topics in cancer biology, neurobiology, genetics and developmental biology, microbiology and public health, and computational and physical sciences, for example. Additionally ABRCMS offers topics on social issues such as research ethics, unconscious bias, and mentoring. About $70 \%$ of ABRCMS content comes from student presentations in poster and oral sessions organized by discipline and by academic level so that sophomores, juniors, and seniors present in sessions separate from postbaccalaureate and graduate students.

In addition to the scientific aspects of the conference, there is an exhibition hall (350 booths in 2015) where research scientists, graduate students and postdoctoral fellows, and staff and advisors from universities and programs recruit student attendees for summer research (e.g., NSF-funded Research Experiences for Undergraduates sites) and graduate programs. There is no employment recruitment. All exhibitors attend an orientation to learn about the community of students, their needs, and what questions they might ask exhibitors. Each exhibit is staffed by a team of scientists, advisors, staff, and graduate students. The scientists and advisors for research programs discuss research opportunities with students; graduate students who previously attended ABCRMS as an undergraduate frequently return as exhibitors, serving as representatives of the institutions' graduate programs. This arrangement allows early-career graduate students to network and mentor undergraduates and other early-career graduate students seeking information about unique research opportunities and training programs. 
Role Models, Community, and Mentoring. The plenary speakers are chosen because they are notable scientists in their discipline and excellent science communicators. This exposes student attendees to leaders in the scientific community, many of who are women $(\geq 40 \%)$ and racial/ethnic minorities $(\geq 73 \%)$. Further, all attendees have meals together, allowing for informal conversations, thus deepening students' understanding about scientific topics, the nature of science, and science research careers. Equally important is deepening understanding among the research scientists and graduate faculty about student interest and motivation in science and communicating science to a publicly engaged audience in science. The ABRCMS community highly values the sit-down meals with students and uses this time to foster a sense of community and responsibility among attendees to promote diversity in science.

The conference also provides many opportunities for formal and informal mentoring among student peers and between graduate students and undergraduates. All first-time attendees are matched with a peer mentor who is either a graduate student or postbaccalaureate fellow and has previously attended ABRCMS. All peer mentors attend a training session before meeting their protégés.

Poster and Travel Awards. ABRCMS invests much time and funding into providing scientific judging for all student poster and oral presentations in order to provide students with developmental feedback and award the top presenters. In 2015, there were 492 principal investigators and postdoctoral scientists who served as judges. Only scientists who indicate they dedicate at least $50 \%$ of their time to research are invited to serve as judges. Judges attend a training session the first morning of the conference. Lead judges are selected within each discipline, and judges discuss sample cases to establish reliability on scoring award criteria. All posters and oral presentations are judged on a scale from 1 (poor) to 5 (excellent) on the following dimensions: 1) hypothesis/objective/problem statement; 2) method; 3) results; 4) conclusion/discussion; 5) overall presentation and ability to answer questions; and 6) poster/PowerPoint quality, organization, and clarity. For poster sessions, all judges talk with each presenter, complete a score sheet, and provide immediate oral feedback to the presenter. For oral presentation sessions, the judges lead a postsession discussion to talk with the group of presenters and provide group feedback. Each student has the opportunity to win one presentation award. In addition, students can receive travel awards by submitting an essay on their career goals along with their abstract submission.

Given the scope, size, and reach of the conference, attending and presenting research at ABRCMS can be an intervention to increase the representation of women and racial/ethnic minority students in the life sciences and all STEM disciplines. The ABRCMS conference itself meets the conditions and the frameworks proposed to increase persistence in STEM. Graham and colleagues (2013), for example, suggested three components of programs that "inspire" STEM students-early research experiences, active learning in courses, and membership in STEM learning communities. With its emphasis on both undergraduate research experiences and the immersion of students in the 4-day STEM learning community, ABRCMS provides the core opportunities to both "identify as a scientist" and "learn science" (Graham et al., 2013, p. 1455). ABRCMS is also a "scientific community" that serves as an "agent of social influence" by allowing students to see their roles as scientists (identity) and to espouse their values as scientists (research and dissemination; Estrada et al., 2011). These frameworks identify, at their core, various psychological constructs that improve student persistence-self-efficacy (the confidence and belief in ones' abilities) and motivation (the willingness to engage; Dweck, 1986; Bandura, 1989, 1997). As previously mentioned, there is a large body of literature documenting the positive effects of participating in undergraduate research (i.e., likelihood of pursuing graduate school, increased science self-efficacy, research confidence, and sense of belonging in science), but what role does attending and presenting research at an undergraduate conference targeted at URM students in STEM play in contributing to these effects?

\section{Student Benefits of Attending and Presenting at Undergraduate Research Conferences}

A common feature of undergraduate research training experiences and programs is to present one's research in an oral or poster presentation (Lopatto, 2007). For example, summer training programs often culminate in a symposium for trainees to present their projects. When the quality of work is substantial, faculty advisors may encourage trainees to present their research at regional or national professional conferences. ABRCMS provides a professional forum in which undergraduates and postbaccalaureates can present their work in a supportive environment.

A unique feature of ABRCMS is that it is geared toward racial/ethnic minority students who are underrepresented in the sciences (URMs), a group that includes blacks/African Americans, Hispanics/Latino/as, Native Americans/American Indians, Alaska Natives, and Pacific Islanders. In 2015, among the 2086 undergraduate and postbaccalaureate attendees (51\% of attendees), $61 \%$ were women; $36 \%$ were men; $42 \%$ were black/ African American; 35\% were Hispanic or Latino/a; 6\% were Caucasian; 6\% were Asian American; $2 \%$ were Native American, Pacific Islander, or Alaska Natives; 9\% did not report their race/ethnicity; and 3\% reported their gender as "other" or did not report their gender. The representation of black/AfricanAmerican and Hispanic/Latino/a students at ABRCMS is higher than that at many college campuses, particularly predominantly white universities. Indeed, a major benefit of attending a minority-focused conference is that students encounter scientists from similar cultural and ethnic backgrounds, with students reporting interacting with "scientists who 'look like me." A study conducted by researchers collaborating with the Society for the Advancement of Chicanos/Hispanics and Native Americans in Science found that minority students who had more research experience (i.e., presenting at conferences) and greater involvement in the science community (i.e., networking with other students) had stronger identities as scientists (Chemers et al., 2011). Many URMs report a sense of pride in seeing so many minority scientists who "look like me" (Chemers et al., 2011).

A study with student attendees at the American Chemical Society (ACS) conference in 2007 or 2008 was conducted. In contrast to ABRCMS, this conference is primarily targeted to professional researchers (e.g., PhDs), but as at most professional conferences, a proportion of attendees and presenters are undergraduate and graduate students $(\sim 37 \%$ at ACS; 
TABLE 1. Survey response rates by year of attendance, gender, and race/ethnicity

\begin{tabular}{|c|c|c|c|c|c|c|}
\hline Demographic & 2008 & 2009 & 2010 & 2011 & All & Survey respondents \\
\hline Black/African American & 565 & 577 & 713 & 728 & $2583(55 \%)$ & $48 \%$ \\
\hline Pacific Islander or Alaska Native & 24 & 22 & 19 & 15 & $80(2 \%)$ & $2 \%$ \\
\hline Hispanic or Latina/o & 404 & 375 & 403 & 438 & $1620(35 \%)$ & $41 \%$ \\
\hline Native American & 15 & 9 & 19 & 23 & $66(2 \%)$ & $2 \%$ \\
\hline Caucasian & 24 & 26 & 42 & 34 & $126(3 \%)$ & $8 \%$ \\
\hline Total & 746 & 782 & 944 & 1094 & 3566 & $15 \%$ \\
\hline
\end{tabular}

ACS, 2016). The researcher found the main motivation for attending the conference was to present a poster, followed by having fun, listing the conference on their résumé, and meeting prospective graduate advisors (Mabrouk, 2009). There was an interesting difference among URMs and non-URMs in that non-URMs were more likely to report the motive to have fun, whereas URMs were more likely to report attending to develop their presentation skills, see what it is like to be a scientist, and develop their self-confidence. While this study seems to be the first published educational study to investigate students' motivations for attending a research conference and the types of activities they engaged in, it has limitations. The sample was predominantly Caucasian, representing only 7\% black/African American and 4\% Hispanic/Latino/a students. Through single-item measures, the survey assessed perceived changes in intentions to pursue graduate study and careers in science. One question asked participants to report the greatest benefit of attending the conference, with options including technical information and developing self-confidence, but these items were not assessed independently. Clearly more research is needed to investigate the specific role that conference attendance and presentations play in the undergraduate research experience and pathway to a scientific career. The present study contributes to this growing body of literature.

\section{Evaluation Questions}

An evaluation study was designed to assess the effects of ABRCMS on its participants using the overarching evaluation questions of "What are former ABRCMS attendees currently doing?" and "How did ABRCMS make a difference in their educational and professional lives?" More specifically, this study examined the evaluation data to answer the following questions: 1) What are the benefits of a) attending, b) presenting at, and c) receiving awards at ABRCMS? 2) Does a) attending, b) presenting at, and c) receiving awards at ABRCMS predict greater intentions to attend graduate school and pursue a research career? 3) Which of the benefits of attending ABRCMS predict intentions to pursue a research degree in graduate school and intentions to pursue a research career? 4) Does the frequency of attending ABRCMS or the number of times presenting research at ABRCMS moderate relationships between benefits and intentions to pursue graduate school and a research career? 5) Are the relationships between benefits, attendance, awards, and presenting at ABRCMS similar across race/ethnicity and gender groups?

\section{METHODS}

\section{Sampling and Response Rate}

Approximately 3566 conference attendees, each of whom attended one or more of the annual conferences from 2008 to 2011, were sent a questionnaire electronically. Only those who indicated they were a junior, senior, or postbaccalaureate on their ABRCMS registration form received the invitation and a link to the questionnaire. The students were sent the initial invitation to participate on July 23, 2013 (via their email address used for conference registration), and an email reminder was sent on August 9, 2013.

At the close of the survey, 533 participants completed the survey, with a final response rate of $15 \%$. Response rates varied by year of conference attendance, gender, and race/ethnicity (see Table 1). Attendees from 2008 represented 21\% $(n=746)$ of the invited population, with 91 participating, reflecting $17 \%$ of the final sample; $22 \%(n=782)$ of the invited population attended in 2009 , and 98 participated, reflecting $18 \%$ of the final sample; $26 \%(n=944)$ of the invited population attended in 2010, and 143 participated, reflecting $27 \%$ of the final sample; and $31 \%(n=1094)$ of the invited population attended in 2011 , and 200 participated, reflecting $38 \%$ of the final sample. Thus, students who attended ABRCMS more recently (e.g., 2010, 2011) were more likely to participate, representing 65\% of the sample. Women made up $64 \%$ of the invited population but constituted $68 \%$ of the sample; thus, women were slightly more likely to participate than men. Black/African-American students made up 55\% of the invited population but represented only $48 \%$ of respondents, whereas students from Asian-American, Hispanic/Latina/o, and Caucasian backgrounds were overrepresented in the respondent sample (see Table 1). The reasons for race/ethnicity and gender differences in response rates are unknown. We believe the overall low response rate $(15 \%)$ is due in part to the use of old email addresses (ones from students' former institutions) and the retrospective nature of the survey. As mentioned previously, recent participants were more likely to complete the survey than those who attended ABRCMS three or more years ago.

\section{Participants}

The demographics of the survey respondents were compared with those of all registrants across the years 2008-2011. These data suggest the respondents are generally representative of all participants (see Table 1). It should be noted that 61 (11\%) respondents did not report their gender or race/ethnicity and are excluded from analyses of gender and race/ethnicity. 
The majority of the 12 discipline categories were represented in proportion to conference registrants. Disciplines that had equal representation in the sample and conference registration included: molecular biological sciences/cell biology, microbiology, neuroscience, and developmental biology/genetics. Disciplines with over- and underrepresentation reflecting $\pm 5 \%$ included: cancer biology $(+5 \%)$, immunology $(+3 \%)$, engineering/mathematics/physics $(+2 \%)$, social/behavioral sciences/public health $(+2 \%)$, biochemistry $(-1 \%)$, cell biology $(-1 \%)$, chemical sciences $(-2 \%)$, and physiology $(-2 \%)$. The majority of students presenting posters during the 2008-2011 period were seniors (47\%), followed by juniors (29\%), with postbaccalaureate and graduate students constituting $12 \%$ of presenters. Participants were also asked to indicate their current educational level or occupational status. The majority of respondents were in graduate or professional school (65.6\%).

\section{Instrument}

Besides requesting demographic information, the survey also asked participants questions about the following areas: general participation (frequency of attendance, presentations, and awards), education and career choices (major, retention in STEM, science self-efficacy, postbaccalaureate plans), mentoring (number of contacts, mentors, advisors, and continued relationships), current situation (enrolled in graduate school, degree and graduation date and plans, and/or employment information), professional activities and scholarship (research experiences, publications, presentations, professional society membership), and impact of attending ABRCMS (positive and negative, and effects on educational and professional choices). The majority of the items were developed for this particular study and were designed to address the previously identified evaluation questions. Some of the items - especially those related to students' feelings of science self-efficacy, research confidence, and their sense of belonging in science-were based on previous research about STEM persistence (Lent et al., 1994; Kardash, 2000; Lopatto, 2004; Seymour et al., 2004; Pfund et al., 2006; Byars-Winston et al., 2010). Two of the survey questions in particular (questions 6 and 7; see the Supplemental Material) were created to be consistent with the literature on undergraduate STEM education. They were developed to evaluate students' experiences at ABRCMS and the consequences of attending. Although they were based on the literature about STEM retention, the items themselves were adapted to assess students' perceptions about how they were affected by attendance at ABRCMS.

ABRCMS Participation. Items in the questionnaire assessed students' frequency of attending and presenting at ABRCMS. Frequency was a sum of the responses to "Which of the following ABRCMS meetings did you attend as an undergraduate student (please check all that apply)?," with the options of 20072013, and participants could write in other years, including 2005 and 2006. Frequency of presenting was assessed by the item "How many times did you present a poster or an oral presentation at ABRCMS as an undergraduate student?," with the options of "never," "once," "twice," "three times," "four or more times." Participants were able to write in a different frequency if necessary. These responses were converted to a scale of 0-4. The final question assessed how many awards the students received: "If you presented a poster or an oral presentation at
ABRCMS as an undergraduate student, how many awards did you receive?" The awards included both presentation and travel awards, since they are both competitive and based on merit. Response options were "none," "one," and "two." Participants were able to write in a different amount if necessary. This item was scored on a scale of $0-2$.

Undergraduate Research Experience. We assessed undergraduate research experience with the item "How many research experiences did you have as an undergraduate student? (One semester or one summer program counts as 1.)" Participants typed in their response in the open-ended dialogue box. This variable is used as a control in analyses when feasible.

Psychological Variables. The psychological variables of interest included science self-efficacy, research confidence, and sense of belonging in science. Science self-efficacy was assessed by two items rated on a scale of 1 (strongly disagree) to 5 (strongly agree). The items included "I felt more motivated to be a scientist because of attending" and "I felt more capable of being a scientist because of attending." The items were highly correlated, $r(507)=0.802, p=0.001$, and averaged. Research confidence was assessed by five items rated on a scale of 1 (decreased a lot) to 5 (increased a lot). Items began with "For each statement, please indicate how your level of confidence changed, if at all, because of attending ABRCMS. My confidence level ..." Sample items included "Make important contributions to a research team" and "Present a research talk or poster." The scale was internally consistent ( $\alpha=0.821)$, and items were averaged. Finally, sense of belonging was assessed by three items rated on a scale of 1 (strongly disagree) to 5 (strongly agree). Sample items included "I felt part of the scientific community" and "I felt like I 'fit in' at the conference." The items had internal consistency $(\alpha=0.819)$ and were averaged.

Outcome Variables. Four outcome variables included presenting at future conferences, publications after ABRCMS, intentions to pursue graduate school, and intentions to pursue a career in science. Presenting at future conferences was assessed by the question "How many poster and/or oral presentations have you conducted since attending ABRCMS?" Response options included 0-5 and "other," allowing participants to write in an alternative amount. Publication activity was assessed by the question "How many research articles have you published since attending ABRCMS?" Response options include $0-5$ and "other," allowing participants to write in an alternative amount. Intentions to pursue graduate school were assessed by two questions. Participants were asked "How did your career goals change, if at all, because of attending ABRCMS (please check all that apply)?" Options included "I decided to pursue: a master's degree, a doctoral degree, an $\mathrm{MD} / \mathrm{PhD}$, a professional degree in the sciences (veterinary, pharmacy, medical)." Participants who selected any one of these options were categorized with a "Yes" response for plans to attend graduate school. Several respondents chose "My career goals stayed the same" for this question (59.2\%). To determine these respondents' graduate school intentions, we used their responses to a previous question assessing their confidence in their ability to "Pursue a graduate degree in science" and "Complete a graduate degree in science." Respondents who marked a slight or large increase 
in their confidence were categorized with a "Yes" response for plans to attend graduate school. Intention to pursue a career in science was assessed by the item "What do you plan to do after graduating with this degree?" Participants who selected a response that indicated a science career, including faculty member, research scientist, science but not education, science education, and industry were coded as "Yes" for career intentions in science.

\section{Data Analysis Procedures}

Descriptive statistics and chi-squared analyses were computed to examine trends by gender and race/ethnicity in attendance, presenting, and awards. Bivariate correlations (Pearson's $r$ ) were computed to examine the relationships between 1) attending, 2) presenting, and 3) frequency of earning awards at ABRCMS and several positive outcomes including science self-efficacy, research confidence, sense of belonging in science, publications, and presenting at future conferences. Multiple linear regression was used to assess the strength of the predictors (attendance, presenting, awards) as a group to determine the extent to which each predictor accounts for unique variance in the positive outcomes. Logistic regression analyses were computed to test attending, presenting, and frequency of earning awards as individual and collective predictors of students' intentions to pursue graduate school and research careers (binary Yes/No variables). Tests of the simple slopes for interactions are computed at $1 \mathrm{SD}$ below the mean (lower), at the mean (average), and 1 SD above the mean (above) using Hayes' (2013) PROCESS model macro in SPSS. Where appropriate, effect sizes ( $R^{2}$, partial eta-squared, and Cohen's $\left.d\right)$ are reported along with $95 \%$ confidence intervals.

All analyses, except the zero-order correlations, were computed controlling for prior undergraduate research experience in order to isolate the benefits of attending, presenting, and earning awards at ABRCMS above and beyond the benefits of participating in undergraduate research. In addition, to determine whether the benefits of attending, presenting, and earning awards at ABRCMS were present only for students for whom the conference was a formative experience, we conducted all analyses for the entire sample and separately for students who only attended ABRCMS and no other conferences (ABRCMS was their formative experience).

\section{RESULTS \\ Benefits of ABRCMS}

Attending. The frequency of attending ABRCMS is presented in Table 2. The majority of attendees, regardless of gender or race/ethnicity, were first-time attendees. Although there were no gender differences in the number of ABRCMS conferences attended, URMs were likely to attend more ABRCMS conferences $(\mathrm{M}=1.54, \mathrm{SD}=0.726)$ than non-URMs $(\mathrm{M}=$ $1.20, \mathrm{SD}=0.401), t(468)=3.21, p=0.001, d=0.30$, mean difference $=0.349,95 \%$ CI $[0.135,0.563]$. Frequency of attending ABRCMS is marginally related to science self-efficacy, $r(508)=0.086, p=0.052$, such that more frequent attendance was related to higher science self-efficacy (see Table 3). Frequency of attendance was related to research confidence, $r(475)=0.104, p=0.024$, indicating that students with higher frequency of attendance reported higher research self-confidence.
TABLE 2. Frequency of attendance, presentations, and awards by gender and race/ethnicity

\begin{tabular}{|c|c|c|c|c|}
\hline & URM & Non-URM & Women & Men \\
\hline \multicolumn{5}{|l|}{ Conference attendance } \\
\hline First-time attendee & $245(58 \%)$ & $37(80 \%)$ & $195(61 \%)$ & $85(57 \%)$ \\
\hline Second attendance & $134(32 \%)$ & $9(20)$ & $95(30 \%)$ & $49(33 \%)$ \\
\hline Third attendance & $38(9 \%)$ & 0 & $26(8 \%)$ & $12(8 \%)$ \\
\hline Fourth attendance & $7(2 \%)$ & 0 & $4(1 \%)$ & $4(3 \%)$ \\
\hline \multicolumn{5}{|l|}{ Conference presentation } \\
\hline Never presented & $35(8 \%)$ & $2(4 \%)$ & $25(8 \%)$ & $12(8 \%)$ \\
\hline First-time presenter & $246(58 \%)$ & $36(80 \%)$ & $195(31 \%)$ & $87(58 \%)$ \\
\hline Second presentation & $113(27 \%)$ & $7(16 \%)$ & $82(26 \%)$ & $38(25 \%)$ \\
\hline Third presentation & $23(6 \%)$ & 0 & $13(4 \%)$ & $10(7 \%)$ \\
\hline Fourth presentation & $5(1 \%)$ & 0 & $3(1 \%)$ & $3(2 \%)$ \\
\hline \multicolumn{5}{|l|}{ Award recipients } \\
\hline No award & $268(70 \%)$ & $33(77 \%)$ & $220(76 \%)$ & $81(60 \%)$ \\
\hline One award & $104(27 \%)$ & $10(23 \%)$ & $64(22 \%)$ & $50(37 \%)$ \\
\hline Two awards & $10(3 \%)$ & 0 & $5(2 \%)$ & $5(3 \%)$ \\
\hline
\end{tabular}

Frequency of attending ABRCMS was also related to sense of belonging, $r(509)=0.102, p=0.021$, such that students with more frequent attendance had greater sense of belonging in science. Frequency of attending was also related to frequency of presenting research at a future conference, $r(434)=0.10$, $p=0.038$, indicating that the more students attend ABRCMS the more frequently they present research at other conferences. Although not significant, the relationship between frequency of attending ABRCMS and number of publications was positive (see Table 3). The same relationships were found among the formative experience sample, though the correlations were higher for research confidence and sense of belonging (see Table 2).

Logistic regression indicated that frequency of attending ABRCMS significantly predicted students' intentions to pursue a research degree in graduate school, after controlling for undergraduate research experience, $\chi^{2}(1, n=524)=15.19, p=0.001$, $\mathrm{B}=0.485, R^{2}=0.042, \exp (\mathrm{B})=1.625,95 \%$ CI $[1.263,2.09]$. The more frequently students attended ABRCMS, the greater their intention to pursue a research degree in graduate school.

Frequency of attending ABRCMS did not predict intentions to pursue a research career. The same results were found for the formative experience sample, for both intentions to pursue a research degree in graduate school, $\chi^{2}(1, n=322)=7.44$, $p=0.006, \mathrm{~B}=0.442, R^{2}=0.031, \exp (\mathrm{B})=1.556,95 \% \mathrm{CI}$ $[1.125,2.153]$, and intentions to pursue a research career (not significant).

Presenting. The frequency of presenting at ABRCMS is presented in Table 2 . The majority of attendees, regardless of gender or race/ethnicity, were first-time presenters. Although there were no gender differences in the frequency of presenting, URMs had marginally greater frequency of presenting $(\mathrm{M}=1.33$, $\mathrm{SD}=0.754)$ than non-URMs $(\mathrm{M}=1.11, \mathrm{SD}=0.438), t(465)=$ $1.91, p=0.057, d=0.177$, mean difference $=0.218,95 \% \mathrm{CI}$ $[0.007,0.443]$. Frequency of presenting at ABRCMS was not significantly related to science self-efficacy or sense of belonging in science (see Table 3). However, frequency of presenting 
TABLE 3. Benefits of attending, presenting at, and receiving an award at ABRCMS

\begin{tabular}{|c|c|c|c|c|c|c|c|c|}
\hline \multirow[b]{2}{*}{ Predictor outcome } & \multicolumn{4}{|c|}{ Full sample } & \multicolumn{4}{|c|}{ Formative experience } \\
\hline & $r$ & $p$ & $r 2$ & $n$ & $r$ & $p$ & $r 2$ & $n$ \\
\hline \multicolumn{9}{|l|}{ Attending } \\
\hline Self-efficacy & 0.086 & 0.052 & 0.007 & 510 & 0.095 & 0.097 & 0.009 & 306 \\
\hline Confidence & 0.104 & 0.024 & 0.01 & 477 & 0.143 & 0.018 & 0.02 & 274 \\
\hline Belonging & 0.102 & 0.021 & 0.01 & 511 & 0.142 & 0.013 & 0.02 & 307 \\
\hline Publications & 0.066 & 0.154 & 0.004 & 461 & 0.072 & 0.243 & 0.005 & 267 \\
\hline Future conference & 0.100 & 0.038 & 0.01 & 436 & NA & NA & NA & NA \\
\hline \multicolumn{9}{|l|}{ Presenting } \\
\hline Self-efficacy & 0.055 & 0.212 & 0.003 & 507 & 0.051 & 0.377 & 0.003 & 303 \\
\hline Confidence & 0.159 & 0.001 & 0.025 & 474 & 0.210 & 0.001 & 0.044 & 271 \\
\hline Belonging & 0.047 & 0.291 & 0.002 & 508 & 0.052 & 0.370 & 0.003 & 304 \\
\hline Publications & 0.069 & 0.140 & 0.005 & 459 & 0.004 & 0.946 & 0.000 & 265 \\
\hline Future conference & 0.121 & 0.012 & 0.015 & 433 & NA & NA & NA & NA \\
\hline \multicolumn{9}{|l|}{ Award } \\
\hline Self-efficacy & 0.112 & 0.016 & 0.013 & 432 & 0.082 & 0.179 & 0.007 & 269 \\
\hline Confidence & 0.207 & 0.001 & 0.043 & 432 & 0.175 & 0.006 & 0.03 & 244 \\
\hline Belonging & 0.089 & 0.058 & 0.008 & 459 & 0.071 & 0.247 & 0.005 & 247 \\
\hline Publications & 0.113 & 0.021 & 0.013 & 419 & 0.091 & 0.162 & 0.008 & 239 \\
\hline Future conference & 0.133 & 0.008 & 0.018 & 396 & NA & NA & NA & NA \\
\hline
\end{tabular}

Outcome variables include science self-efficacy (Self-efficacy), research confidence (Confidence), sense of belonging in science (Belonging), number of publications (Publications), and frequency of presenting at conferences after ABRCMS (Future conference). The formative experience data reflect analyses restricted to participants whose sole conference experience is ABRCMS. NA = not applicable.

was significantly related to research self-confidence, $r(472)=$ $0.159, p=0.001$, such that greater frequency of presenting was related to higher research self-confidence. Frequency of presenting was also positively related to frequency of presenting at a future conference other than ABRCMS, $r(431)=0.121$, $p=0.012$, indicating that more frequently presenting at ABRCMS was related to more frequently presenting at other conferences. Although not significant, the relationship between frequency of presenting at ABRCMS and number of publications was positive (see Table 3 ). The same relationships were found among the formative experience sample, though the correlation was higher for research confidence (see Table 3).

Logistic regression indicated that frequency of presenting at ABRCMS significantly predicted students' intentions to pursue a research degree in graduate school, $\chi^{2}(1, n=521)=13.01$, $p=0.001, \mathrm{~B}=0.431, R^{2}=0.036, \exp (\mathrm{B})=1.5386,95 \% \mathrm{CI}$ $[1.21,1.955]$. The more frequently students presented their research at ABRCMS, the greater their intention to pursue a research degree in graduate school. Frequency of presenting at ABRCMS did not predict intentions to pursue a research career. However, frequency of presenting research at future conferences did predict intentions to pursue a research career, $\chi^{2}(1$, $n=89)=13.70, p=0.001, \mathrm{~B}=0.575, R^{2}=0.328, \exp (\mathrm{B})=1.78$, $95 \%$ CI $[1.279,2.469]$, such that greater frequency of presenting predicted greater intentions to pursue a research career. The same result was found for the formative experience sample for intentions to pursue a research degree in graduate school, $\chi^{2}(1, n=319)=9.755, p=0.002, \mathrm{~B}=0.485, R^{2}=0.041$, $\exp (\mathrm{B})$ $=1.624,95 \%$ CI $[1.187,2.222]$.

Earning Awards. Among the 475 participants who presented research, $28 \%$ won at least one award (see Table 2). The majority of attendees, regardless of gender or race/ethnicity, have never received awards. Although there were no race/ethnicity differences in the number of awards received at ABRCMS, there was a gender difference favoring males $(\mathrm{M}=0.441, \mathrm{SD}=0.568$; females: $\mathrm{M}=0.256, \mathrm{SD}=0.475), t(423)=3.51, p=0.001$, $d=0.341$, mean difference $=0.185,95 \%$ CI $[0.082,0.289$ ] Number of awards received is positively related to science self-efficacy, $r(430)=0.112, p=0.016$, such that the more frequently students won awards, the higher their science self-efficacy. There also was a positive relationship between earning awards and research confidence, $r(430)=0.207, p=0.001$; number of publications, $r(417)=0.113, p=0.021$; and frequency of attending future conferences, $r(394)=0.133, p=$ 0.008 . There was a marginally positive relationship between frequency of awards and sense of belonging in science, $r(457)=$ $0.089, p=0.058$. The only significant relationship for the formative sample was research confidence, $r(242)=0.175, p=0.006$. The lack of correlations for this subsample is likely because these students were less likely to receive awards than students who have presented at multiple conferences, $t(473)=1.96, p=0.05$.

Logistic regression indicated that frequency of earning awards at ABRCMS marginally predicted students' intentions to pursue a research degree in graduate school, $\chi^{2}(1, n=470)=$ 2.93, $p=0.087, \mathrm{~B}=0.316, R^{2}=0.011, \exp (\mathrm{B})=1.37,95 \% \mathrm{CI}$ $[0.953,1.976]$. Although the result is not statistically significant, the direction of the relationship is as predicted (positive); namely, the more frequently students earned awards at ABRCMS, the greater their intention to pursue a research degree in graduate school. Earning an award at ABRCMS did not predict intentions to pursue a research career. There were no significant relationships between earning awards and intentions to pursue graduate education or careers in research among the formative experience sample, again because very few had won awards. 
Comparison. All three predictors-attending, presenting at, and earning awards at ABRCMS - are significantly related to students' intentions to earn a research degree in graduate school. A logistic regression in which all three variables were entered as predictors indicated that attending $(B=0.371, p=0.04$, $\exp (\mathrm{B})$ $=1.23,95 \% \mathrm{CI}[0.843,1.81])$, was the only significant predictor of graduate school intentions, $\chi^{2}(4, n=468)=19.89, p=0.001$, $R^{2}=0.055$ (presenting: $\mathrm{B}=0.210, p=0.279$; award: $\mathrm{B}=0.253$, $p=0.185$ ). Among the formative experience sample, the model with all three predictors was significant; however, the best predictor of graduate school intentions was frequency of presenting research, and the relationship was marginal, $\chi^{2}(4, n=281)=$ $12.99, p=0.011, R^{2}=0.061, \mathrm{~B}=0.425, p=0.104$, $\exp (\mathrm{B})=$ $1.53,95 \%$ CI $[0.916,2.56]$. The models predicting intentions to pursue a science career were not significant for either the full sample or the formative experience sample.

\section{Psychological Predictors and Moderators of Intentions to Pursue Graduate School and a Research Career}

Of the three psychological outcomes (science self-efficacy, research confidence, sense of belonging), research confidence gained from attending ABRCMS was the strongest predictor of graduate school plans, $\mathrm{B}=0.425, p=0.009$, $\exp (\mathrm{B})=1.53,95 \%$ CI $[1.11,2.11]$, followed by science self-efficacy, $\mathrm{B}=0.366, p=$ $0.024, \exp (B)=1.44,95 \%$ CI $[1.05,1.98], \chi^{2}(4, n=472)=$ $32.37, p=0.001, R^{2}=0.089$. Specifically, greater research confidence and science self-efficacy each predicted greater intentions to pursue graduate school in STEM. Sense of belonging was not a significant predictor ( $\mathrm{B}=0.038, p=0.847$ ). Only research confidence predicted intentions to pursue a research career, $\chi^{2}(4, n=98)=22.99, p=0.001, \mathrm{~B}=1.14, R^{2}=0.28$, $\exp (B)=3.13,95 \%$ CI $[1.256,7.815]$, such that greater confidence predicted greater intentions. The same relationships for graduate school intentions were found for the formative experience sample (research confidence: $\mathrm{B}=0.457, p=0.027$, $\exp (\mathrm{B})$ $=1.58,95 \%$ CI $[1.05,2.37]$; science self-efficacy: $\mathrm{B}=0.476, p=$ 0.033, $\exp (B)=1.61,95 \%$ CI [1.04, 2.49]; sense of belonging: $\mathrm{B}=-0.099, p=0.709, \chi^{2}(4, n=271)=20.94, p=0.001, R^{2}=$ 0.099). Similar to the full sample analysis, research confidence was the only predictor of intentions to pursue a research career among the formative experience sample (research confidence: $\mathrm{B}=2.26, p=0.008, \exp (\mathrm{B})=9.61,95 \%$ CI $[1.81,51.01], \chi^{2}(4$, $n=50)=18.41, p=0.001, R^{2}=0.411$ ).

The relationship between research confidence and intentions to pursue graduate school is moderated by frequency of attending ABRCMS, $\chi^{2}(4, n=473)=42.73, p=0.001, R^{2}=0.115$. In the interaction model, the direct relationship of research confidence with intentions was significant $(B=0.676, p=0.001,95 \%$ CI $[0.373,0.980])$, the direct relationship of frequency of attending was significant ( $\mathrm{B}=0.547, p=0.001,95 \%$ CI $[0.253$, $0.840])$, and the interaction was significant $(\mathrm{B}=0.582, p=$ $0.016,95 \%$ CI $[0.108,1.057])$. The conditional effect of research confidence on intentions was significant for low conference attendance ( $\mathrm{b}=0.369, p=0.025,95 \%$ CI [0.046, 0.691]), average attendance $(b=0.676, p=0.001,95 \%$ CI $[0.1373,0.980])$ and high attendance $(\mathrm{b}=1.10, p=0.001,95 \%$ CI $[0.568$, 1.625]). Thus, greater research confidence predicted greater intentions to pursue graduate school, and this effect was stronger the more frequently students attended ABRCMS. The interaction was not present for the formative experience sample.
There were no other significant moderating relationships among science self-efficacy, research confidence, and sense of belonging predicting graduate school or science career plans for the full or formative experience sample.

\section{Gender and Racial/Ethnic Differences}

Results indicate there are many benefits for all students, regardless of gender and race/ethnicity, for attending, presenting, and receiving awards at ABRCMS. Although the benefits of attending, presenting, and earning awards at ABRCMS seem to benefit all students, there are differences by gender and race/ethnicity. There were no gender or race/ethnicity differences in intentions to pursue graduate school; however, after controlling for undergraduate research experience, men were marginally more likely than women to intend to pursue a research career, model: $\chi^{2}(2, n=99)=13.181, p=0.001, R^{2}=0.167$; predictor: $\mathrm{B}=0.931, p=0.074, \exp (\mathrm{B})=2.536,95 \%$ CI $[0.915,7.03]$. An examination of this relationship indicated that men had marginally greater research confidence than women, $t(468)=1.84$, $p=0.066, d=0.17$, mean difference $=0.135,95 \%$ CI $[-0.009$, $0.279]$, and this indicated a marginal moderation of the relationship between gender and research career plans, model: $\chi^{2}(3, n=98)=19.07, p=0.001, R^{2}=0.341$; predictor: $\mathrm{B}=1.67$, $p=0.072$, 95\% CI $[-0.148,3.48]$. The marginal interaction between gender and research confidence on research career intentions was significant for low research confidence $(\mathrm{b}=$ $-2.28, p=0.011,95 \%$ CI $[-4.01,-0.531])$, and average confidence $(b=-1.12, p=0.041,95 \%$ CI $[-2.20,-0.047])$, but was not significant for high confidence $(b=0.0242, p=0.976)$. Thus, when women and men had lower or average research confidence, men were more likely to pursue a research career than women; however, when women and men had high research confidence, there were no gender differences in research career intentions. The interaction was not present for the formative experience sample.

Differences emerged between URM and non-URM students regarding degree of science self-efficacy, research confidence, and sense of belonging, after controlling for extent of research experience. Compared with non-URMs $(\mathrm{M}=4.00, \mathrm{SD}=0.955$; 95\% CI [3.74, 4.25]), URMs had higher science self-efficacy (M $=4.29, \mathrm{SD}=0.874 ; 95 \% \mathrm{CI}[4.21,4.38]), F(1,462)=4.61, p=$ $0.032, \eta_{p}^{2}=0.01$. There were no racial/ethnic differences in research confidence. Similar to science self-efficacy, compared with non-URMs ( $M=4.04, \mathrm{SD}=0.876$; 95\% CI [3.83, 4.25]), URMs reported higher sense of belonging $(M=4.31$, $S D=0.701$; $95 \%$ CI $[4.24,4.38]), F(1,463)=5.66, p=0.032, \eta_{p}^{2}=0.02$.

\section{DISCUSSION}

The purpose of this project was to answer several evaluation questions about the possible benefits of attending, presenting, and receiving awards at ABRCMS. Little research has specifically examined attending and presenting research at science conferences as a socializing mechanism to bring URM students into the scientific community, helping them to develop their identities as scientists and to espouse their values as scientists (Estrada et al., 2011). On the basis of the findings, we argue that merely attending ABRCMS is an intervention that benefits URM STEM students in several ways, including developing greater science self-efficacy, research confidence, sense of belonging in science, and intentions to pursue a research degree 
in graduate school. This claim is further bolstered by the finding that, after controlling for extent of undergraduate research experience, the positive benefits of ABRCMS persisted. Further, the benefits were not limited to students for whom attending ABRCMS was a formative experience. Students who have attended ABRCMS multiple times along with other conferences also benefited specifically from attending, presenting at, or earning awards at ABRCMS. Presenting and winning awards at ABRCMS showed similar benefits, including publishing research, future conference attendance, and intentions for graduate school and a research career in science. These results highlight the critical role of attending a minority-oriented research conference in which URMs can develop their research confidence and feel like members of the science community.

The quantitative results from this study highlight the critical role of a minority-oriented research conference in which URMs can experience a safe environment to further develop their science self-efficacy, research confidence, and sense of belonging in the community of scientists. The participants' responses to open-ended comments confirmed that they felt part of a scientific community of practice, and in particular, one where they encounter scientists from similar cultural and ethnic backgrounds. In other words, they described this "community of scientists of color," and explained how this identification affected their motivation and belief in themselves. It affirmed and reaffirmed their desire to attend graduate school, and encouraged them to continue to pursue science. They noted that this was an essential perspective and one that affected them far beyond the 4 days of the event. As evidence of this, the majority of attendees $(64 \%)$ reported making at least one lasting contact at the conference.

\section{Theoretical Implications}

The results are consistent with predictions from SCCT (Lent et al., 1994, 2000, 2005, 2008). The cognitive person variables we assessed, including science self-efficacy and research confidence, each predicted academic intentions in STEM. Specifically, greater science self-efficacy and research confidence each predicted greater intentions to pursue graduate school in STEM. Only research confidence predicted intentions to pursue a research career, such that greater confidence predicted greater intentions.

SCCT also posits that cognitive person variables interact with other characteristic of the person, such as gender and race/ethnicity, to predict academic and career plans. Although all students benefited from attending ABRCMS, there were some interesting differences by gender and race/ethnicity. First, the data indicated men had slightly higher research confidence than women, despite having similar frequency of research experiences. This is not surprising and supports findings from existing work on women's underestimation of ability (Kardash, 2000; Correll 2001, 2004) and tendency to self-stereotype (Sekaquaptewa, 2011). Women's lower research confidence can occur during both the undergraduate research experience stage and during professional development contexts like presenting at research conferences. This general pattern likely reflects the larger issue of the "chilly climate" for women in STEM (Hall and Sandler, 1982, 1984; Byars-Winston et al., 2010; Casad et al., in press, 2016). Interventions can be effective in increasing women's research confidence both through undergraduate research experiences and by presenting at undergraduate research conferences (Campbell and Skoog, 2004). Our study also found that URM students had higher science self-efficacy and sense of belonging than non-URM students. This finding bolsters our claim that ABRCMS serves as an intervention to improve self-efficacy and belonging among URM students in science.

Finally, SCCT states that cognitive person variables interact with aspects of the cultural environment (e.g., supports and barriers) to predict academic and career intentions. Our results show that frequency of attending, presenting, and earning awards at ABRCMS were significantly and positively related to science self-efficacy, research confidence, and sense of belonging, variables that in turn are related to academic and career intentions in STEM. This suggests that involvement in ABRCMS can be considered a cultural environment that provides supports for students in STEM. ABRCMS is a scientific community that serves as an "agent of social influence" by allowing students to identify as scientists, learn science, and espouse their values as scientists (Estrada et al., 2011, p. 1455; Graham et al., 2013).

\section{Training Implications}

Results indicate that attending, presenting at, and earning awards at ABRCMS have many benefits for students in STEM. The benefits of involvement in ABRCMS are above and beyond the known benefits of engaging in undergraduate research. The benefits of ABRCMS seem to be particularly important for URM students. Given these benefits, faculty mentors should consider having their URM mentees attend ABRCMS or similar minority research conferences as part of their undergraduate training programs.

Given the slight gender difference regarding research confidence, changes to the conference and the undergraduate research experience more generally are needed to ensure we serve the needs of women in STEM fields and reduce the gender gap in research confidence. Programming could be added to ABRCMS to address the unique needs of women in STEM, particularly URM women in STEM. For example, mentoring workshops specifically tailored for faculty working with URM women could be included. In addition, a panel discussion with women scientists of color addressing the additional barriers in education and STEM careers related to race and gender issues could help women students boost their science identity, research confidence, and sense of belonging via role models (Dasgupta and Asgari, 2004; Stout et al., 2011; Ramsey et al., 2013).

\section{Limitations}

Although this research provides a novel contribution to the literature on URMs' pursuit of STEM education and careers, it is not without limitations. First, the data reflect self-reports, which may inherently reflect positivity biases. However, given the focus on psychological variables (e.g., belonging) and perceived benefits of attending and presenting at ABRCMS, self-report was the most viable way to assess these constructs. Second, the data are correlational and cross-sectional, which limits claims of causality. Future research can take a longitudinal approach, looking at changes over time to strengthen causal claims. Third, the response rate for this study was lower than desired. We attribute the lower response rate to the difficulty of contacting 
past conference attendees who likely graduated and moved to another university or pursued careers in industry. We relied on ABRCMS registration records to contact attendees. In some cases, program directors batch enrolled students in their programs, which limited our access to individual student attendees' email addresses. This claim is bolstered by the fact that there were higher response rates among attendees from more recent conferences. Nevertheless, the demographics of the respondents reflect the makeup of ABRCMS attendees, and we therefore believe the responses are representative. Finally, we controlled for undergraduate research experiences in our analyses to isolate the benefits of ABRCMS. However, the measure of research experience was a frequency measure (e.g., number of total semesters or summer programs) and did not assess the quality of these experiences. Indeed fewer high-quality experiences can be more beneficial than more frequent lower-quality experiences. Future research can further assess undergraduate research experience quality and investigate how these benefits are unique to attending ABRCMS or similar undergraduate research conferences.

\section{CONCLUSION}

Lack of diversity affects the field of science in multiple ways. Besides the dearth of scientists and role models for students, the quality and "outputs" of research is affected (Valantine and Collins, 2015). Diversity in teams is associated with enhanced critical thinking, tendency toward open-mindedness, greater intellectual engagement, and higher-quality products than teams with less diversity (Nemeth, 1995; McLeod et al., 1996; Wildes, 2000; Herring, 2009). Ultimately, less-diverse science teams are problematic for U.S. global competitiveness (National Academy of Sciences, National Academy of Engineering, and Institute of Medicine, 2010). Future research should examine the role of professional research conferences as change agents in increasing the representation of women and racial/ethnic minorities in STEM fields.

\section{ACKNOWLEDGMENTS}

We are especially grateful to members of the ABRCMS Steering Committee, chaired by Clifford W. Houston, for setting the direction of the conference and connecting students to scientists, and to the members of the ABRCMS Logistics Team, led by Irene $\mathrm{W}$. Hulede, for providing a high-quality professional scientific conference for students. ABRCMS is supported by the NIGMS of the NIH under award number T36GM073777. Any opinions, findings, and conclusions or recommendations expressed in this paper are those of the authors and do not necessarily reflect the views of the $\mathrm{NIH}$.

\section{REFERENCES}

American Society for Chemistry (2016). Registration Statistics. www.acs.org/ content/acs/en/meetings/nationalmeetings/statistics.html (accessed 17 June 2016)

American Society for Microbiology (2015). ABRCMS Statistics. www.abrcms .org/index.php/abrcms/2014-statistics (accessed 20 December 2015).

Bandura A (1989). Human agency in social cognitive theory. Am Psychol 44, 1175-1184.

Bandura A (1997). Self-Efficacy: The Exercise of Control, New York: Freeman
Berkes E (2007). Practicing biology: undergraduate laboratory research, persistence in science, and the impact of self-efficacy beliefs. PhD Thesis, St. Louis, MO: Washington University.

Byars-Winston A, Estrada Y, Howard C, Davis D, Zalapa J (2010). Influence of social cognitive and ethnic variables on academic goals of underrepresented students in science and engineering: a multiple-groups analysis. J Couns Psychol 57, 205.

Byars-Winston A, Gutierrez B, Topp S, Carnes M (2011). Integrating theory and practice to increase scientific workforce diversity: a framework for career development in graduate research training. CBE Life Sci Educ 10, 357-367.

Campbell A, Skoog G (2004). Preparing undergraduate women for science careers. J Coll Sci Teach 33(5), 24-26.

Casad BJ, Ingalls EA, Petzel ZW (2016). Threatening educational environments and women's success in STEM majors: a comprehensive model. Psychol Women Q (in press).

Chang MJ, Eagan MK, Lin MH, Hurtado S (2011). Considering the impact of racial stigmas and science identity: persistence among biomedical and behavioral science aspirants. J High Educ 82, 564-596.

Chemers M, Hu L, Garcia B (2001). Academic self-efficacy and first year college student performance and adjustment. J Educ Psychol 93, 55-64.

Chemers MM, Zurbriggen EL, Syed M, Goza BK, Bearman S (2011). The role of efficacy and identity in science career commitment among underrepresented minority students. J Soc Issues 67, 469-491.

Correll SJ (2001). Gender and the career choice process: the role of biased self-assessments. Am J Sociol 106, 1691-1730.

Correll SJ (2004). Constraints into preferences: gender, status, and emerging career aspirations. Am Sociol Rev 69, 93-113.

Dasgupta N, Asgari S (2004). Seeing is believing: exposure to counterstereotypic women leaders and its effect on the malleability of automatic gender stereotyping. J Exp Soc Psychol 40, 642-658.

Dweck CS (1986). Motivational processes affecting learning. Am Psychol 41 $1040-1048$

Estrada M, Woodcock A, Hernandez PR, Schultz PW (2011). Toward a model of social influence that explains minority student integration into the scientific community. J Educ Psychol 103, 206-222.

Graham MJ, Frederick J, Byars-Winston A, Hunter AB, Handelsman J (2013). Increasing persistence of college students in STEM. Science 341, 14551456.

Hall RM, Sandler BR (1982). The Classroom Climate: A Chilly One for Women? Washington, DC: Association of American Colleges.

Hall RM, Sandler BR (1984). Out of the Classroom: A Chilly Campus Climate for Women?, Washington, DC: Association of American Colleges.

Hayes AF (2013). Introduction to Mediation, Moderation, and Conditional Process Analysis: A Regression-Based Approach, New York: Guilford.

Herring C (2009). Does diversity pay? Race, gender, and business case for diversity. Am Sociol Rev 74, 208-224.

Kardash CM (2000). Evaluation of an undergraduate research experience: perceptions of undergraduate interns and their faculty mentors. J Educ Psychol 92, 191-201.

Lent RW, Brown SD, Hackett G (1994). Toward a unifying social cognitive theory of career and academic interest, choice, and performance. J Vocat Behav 45, 79-122

Lent RW, Brown SD, Hackett G (2000). Contextual supports and barriers to career choice: a social cognitive analysis. J Couns Psychol 47, 36-49.

Lent RW, Brown SD, Sheu HB, Schmidt J, Brenner BR, Gloster CS, Treistman $D$ (2005). Social cognitive predictors of academic interests and goals in engineering: utility for women and students at historically black universities. J Couns Psychol 52, 84-92.

Lent RW, Hackett G, Brown SD (2008). Social cognitive career theory. In: Encyclopedia of Counseling, vol. 4: Career Counseling, ed. FTL Leong, WB Walsh, and PJ Hartung, Thousand Oaks, CA: Sage, 1627-1630

Lopatto $D$ (2003). The essential features of undergraduate research. Counc Undergrad Res Q 24, 139-142.

Lopatto D (2004). Survey of Undergraduate Experiences (SURE): first findings. Cell Biol Educ 3, 270-277. 
Lopatto D (2007). Undergraduate research experiences support science career decisions and active learning. CBE Life Sci Educ 6, 297-306.

Luzzo DA, Hasper P, Albert KA, Bibby MA, Martinelli EA Jr (1999). Effects of self-efficacy-enhancing interventions on the math/science self-efficacy and career interests, goals, and actions of career undecided college students. J Couns Psychol 46, 233.

Mabrouk PA (2009). Survey study investigating the significance of conference participation to undergraduate research students. J Chem Educ 86 1335-1340.

Maton KI, Pollard SA, McDougall Weise TV, Hrabowski FA (2012). Meyerhoff Scholars Program: a strengths-based, institution-wide approach to increasing diversity in science, technology, engineering, and mathematics. Mt Sinai J Med 79, 610-623.

McLeod PL, Lobel SA, Cox TH (1996). Ethnic diversity and creativity in small groups. Small Group Res 27, 248-264.

National Academy of Sciences, National Academy of Engineering, and Institute of Medicine (2010). Expanding Underrepresented Minority Participation: America's Science and Technology Talent at the Crossroads, Washington DC: National Academies Press

National Center for Educational Statistics (2014). Digest of Education Statistics, Washington, DC: U.S. Department of Education, Office of Educational Research and Improvement.

National Institutes of Health (2015). Division of Training, Workforce Development, and Diversity. www.nigms.nih.gov/about/overview/pages/twd.aspx (accessed 20 December 2015).

National Science Foundation (2015). ADVANCE: Increasing the Participation and Advancement of Women in Academic Science and Engineering Careers (ADVANCE). www.nsf.gov/funding/pgm_summ.jsp?pims_id=5383 (accessed 20 December 2015).
Nemeth JC (1995). Dissent as driving cognition, attitudes, and judgments. Soc Cogn 13, 273-291.

Pfund C, Pribbenow CM, Branchaw J, Lauffer SM, Handelsman J (2006). The merits of training mentors. Science 311, 473-474.

Ramsey LR, Betz DE, Sekaquaptewa D (2013). The effects of an academic environment intervention on science identification among women in STEM. Soc Psychol Educ 16, 377-397.

Russell S, Hancock M, McCullough J (2007). Benefits of undergraduate research experiences. Educ Forum 316, 548-549.

Sekaquaptewa D (2011). Discounting their own success: a case for the role of implicit stereotypic attribution bias in women's STEM outcomes. Psychol Inq 22, 291-295.

Seymour E, Hunter AB, Laursen SL, DeAntoni T (2004). Establishing the benefits of research experiences for undergraduates in the sciences: first findings from a three-year study. Sci Educ 88, 493-534.

Stout JG, Dasgupta N, Hunsinger M, McManus MA (2011). STEMing the tide: using ingroup experts to inoculate women's self-concept in science technology, engineering, and mathematics (STEM). J Pers Soc Psychol $100,255-270$

Thakore BK, Naffziger-Hirsch ME, Richardson JL, Williams SN, McGee R (2014). The academy for future science faculty: randomized controlled trial of theory-driven coaching to shape development and diversity of early-career scientists. BMC Med Educ 14, 160.

Valantine HA, Collins FS (2015). National Institutes of Health address the science of diversity. Proc Natl Acad Sci USA 112, 12240-12242.

Wadman M (2012). A workforce out of balance. Nature 486, 304

Wildes DJ (2000). Minorities in Higher Education, 1999-2000. Seventeenth Annual Status Report, Washington, DC: American Council on Education. 